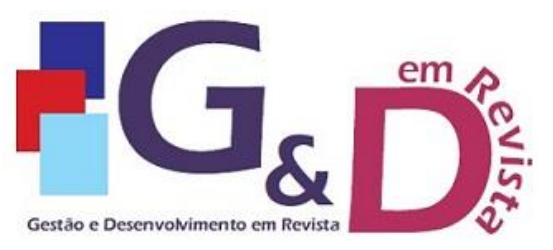

Gestão e Desenvolvimento em Revista

V. 6, N. 2, jul-dez/2020, p. 03-19.

ISSN online: $2446-8738$

Artigo recebido em: 08/07/2020

Artigo aprovado em: 07/12/2020

\title{
AGRICULTURA FAMILIAR E ALIMENTAÇÃO ESCOLAR: ESTRUTURAÇÃO E IMPLEMENTAÇÃO DO PNAE NO MUNICÍPIO DE SÃO GABRIEL- RS
}

\section{Guilherme Vaz Chiesa}

Graduação em Administração. Especialista em Gestão e Inovação no Agronegócio. Atualmente é membro do Núcleo de Inovação Tecnológico (NIT) - UNIPAMPA/Bagé.

E-mail: guilhermevaz@gmail.com

\section{Shirley Grazieli da Sllva Nascimento}

Graduação em Programa Especial de Formação Pedagógica. Mestrado em Agronomia. Doutorado em Sistemas de Produção Agrícola Familiar. Atualmente é Professora Adjunta na Universidade

Federal do Pampa.

E-mail: nascimentos@gmail.com

Mariana Rockenbach de Ávila

Graduação em Tecnologia em Agropecuária. Mestrado em Zootecnia. Doutorado em Zootecnia.

Atualmente é Pesquisadora visitante na Embrapa Clima Temperado.

E-mail: marianaravila@gmail.com

\section{Caroline Ferreira Mainardi}

Graduação em Administração. Mestrado em Administração. Doutorado em Administração. Atualmente é Coordenadora Substituta do Curso de Especialização em Gestão e Inovação no Agronegócio.

E-mail: carolmainaira@hotmail.com

\section{Resumo}

O Programa Nacional de Alimentação Escolar - PNAE, sofreu diversos avanços com a implementação da Lei $n^{\circ}$ 11.947/2009 que refletiu na qualidade e diversidade da alimentação escolar e aumento da renda dos agricultores familiares, impulsionando a economia dos municípios. Todavia, alguns municípios brasileiros não conseguiram atender o percentual de compra mínima estabelecido pelo anterior governo federal. O presente artigo teve como questões norteadoras investigar os motivos que levaram a gestão do município de São Gabriel/RS a não conseguir executar a compra do valor mínimo de $30 \%$ de alimentos oriundos da agricultura familiar para abastecer a merenda escolar do município, identificar quais as maiores dificuldades enfrentadas pelos Agricultores Familiares para participarem do programa e analisar quais as oportunidades que estes percebem junto ao PNAE. Foi realizada uma pesquisa exploratória, através de imersões a campo em propriedades agrícolas familiares. Os dados foram coletados através da realização de entrevistas em profundidade e observação não participante. A interpretação dos resultados se deu através de análise textual de discurso. Os principais resultados evidenciam que existem pontos a serem corrigidos por parte da gestão do programa para que haja uma maior adesão dos agricultores familiares e o município consiga efetivar a participação no programa.

Palavras-chave: Políticas Públicas. Agricultura Familiar. PNAE.

\begin{abstract}
The National School Feeding Program - PNAE, underwent several advances with the implementation of Law No. 11,947/2009, which reflected in the quality and diversity of school meals and increased income for family farmers, boosting the economy of the municipalities. However, some Brazilian municipalities were unable to meet the minimum purchase percentage established by the previous federal government. This article had as guiding questions to investigate the reasons that led the management of the municipality of São Gabriel, RS to fail to execute the purchase of the minimum value of $30 \%$ of food from family farming to supply school meals in the municipality, to identify which one's greatest difficulties faced by Family Farmers to participate in the program and analyze what opportunities they perceive with the PNAE. An exploratory research was carried out, through immersions in the field on family farms. Data were collected through in-depth interviews and nonparticipant observation. The results were interpreted through textual discourse analysis. The main results show that there are points to be corrected by the management of the program so that there is greater adherence by family farmers and the municipality is able to effectively participate in the program.
\end{abstract}

Keywords: Public Policies. Family farming. PNAE. 


\section{INTRODUÇÃO}

Programa Nacional de Alimentação Escolar (PNAE), é uma das mais antigas e permanentes intervenções do governo federal na suplementação alimentar de estudantes (SPINELLI e CANESQUI, 2002). Além de ser considerado um dos mais completos programas de alimentação escolar do mundo, pela gratuidade de refeições e cobertura universal, o programa é tido como uma importante estratégia de Segurança Alimentar e Nutricional (SAN) (TOYOYSHI et al, 2013).

Ao longo dos anos o programa foi sendo modificado e melhorado, o que facilitou maior acesso aos seus benefícios. Até os primeiros anos da década de 90 o gerenciamento e processo de aquisição dos gêneros alimentícios do PNAE eram centralizados, através de licitações, e posteriormente distribuídos para todo país. No ano de 1994 grandes mudanças marcaram uma nova etapa do programa, como maior participação da sociedade no gerenciamento do programa (TRICHES e SCHNEIDER, 2010).

Com a criação do Programa Fome Zero, em 2003, o PNAE foi revisado e na atualização de 16 de junho de 2009, se aprovou a Lei n¹1.947, que dispõe sobre o atendimento da alimentação escolar. Tornou-se obrigatório que, no mínimo, 30\% do total dos recursos financeiros repassados pelo Fundo Nacional de Desenvolvimento em Educação (FNDE) aos estados e municípios deveriam ser utilizados para aquisição de gêneros alimentícios diretamente da agricultura familiar (BRASIL,2009).

A descentralização do processo de aquisição de alimentos caracterizou outra inovação abarcada nesta legislação. As licitações públicas não foram exigidas para os fornecedores caracterizados como agricultores familiares ou cooperativas agrícolas. A última atualização da lei prevê a utilização de chamadas públicas para a compra de gêneros alimentícios junto aos agricultores familiares (TRICHES e SCHNEIDER, 2010).

Com o passar do tempo o PNAE auxiliou na construção de cadeias curtas de abastecimento entre agricultores familiares e escolas, entretanto, existiram dificuldades na implementação desta legislação por parte de alguns municípios. As causas deste revés foram, por vezes, provenientes das dificuldades de planejamento e organização dos agricultores, insuficiência de documentação exigida nas chamadas públicas, impossibilidade do fornecimento constante, problemas com custo e logística, e por parte dos gestores do programa, pouca ou nenhuma articulação com os agricultores familiares (SARAIVA et al, 2013; SOUZA, 2012).

Em vista disso, observou-se a necessidade de estudos que buscassem investigar a implementação e o desenvolvimento do programa de forma local e estrita, buscando compreender a fundo as possibilidades e dificuldades enfrentadas pelos atores envolvidos no processo de comercialização da alimentação escolar.

Diante dessas considerações, o presente estudo busca compreender a execução do PNAE no município de São Gabriel/RS. Para tanto, objetivou-se abordar i) quais os motivos da não aquisição do percentual mínimo de $30 \%$ de alimentos oriundos da agricultura familiar; ii) analisar a percepção dos agricultores familiares sobre o PNAE e iii) os desafios na participação do programa.

\subsection{AGRICULTURA FAMILIAR}

Meados dos anos 90, a expressão "agricultura familiar" adentrou o cenário político brasileiro a fim de substituir as antigas terminologias utilizadas para 
minifundiários, camponeses, agricultores de subsistência, pequenos produtores, etc. A utilização desta nova terminologia estava relacionada com a assinatura do tratado que deu origem ao Mercosul em 1991, o Tratado de Assunção, em adição as atividades políticas-sindicais da Confederação Nacional dos Trabalhadores da Agricultura (CONTAG) e outros grupos que deram origem a Federação dos Trabalhadores na Agricultura Familiar (FETRAF), pois havia muito preconceito, discriminação e até mesmo marginalização destes produtores (NAVARRO, 2010).

Com tais articulações, muitos acordos foram firmados a fim de garantir direitos para os agricultores familiares, como a Portaria Ministerial $n^{\circ} 692$, de 30 de novembro de 1993, que instalou um grupo para tratar dos tópicos específicos relacionados à pequena produção e o Decreto $\mathrm{n}^{\circ} 1.946$ que cria o PRONAF Programa de Fortalecimento da Agricultura Familiar (BRASIL, 1996).

Conforme Tomasseto et al. (2009), determina-se agricultura familiar como um aglomerado de princípios que compreendem características de gerações, onde a mão de obra e gerenciamento são executados por membros da família, e a diversificação da produção na qual vem se desenvolvendo em todos os espaços do mundo.

Diferentemente de grande parte da agricultura patronal, a agricultura familiar compartilha seu local de trabalho com a residência, o que faz da atividade produtiva agropecuária a principal fonte de renda da família, está fica responsável pela gestão organizacional da propriedade como um todo. Segundo a Lei $n^{\circ} 11.326 / 2006$, agricultores e empreendedores familiares são aqueles que possuem atividade no meio rural, onde obtêm renda, a partir de mão de obra dos próprios familiares e em uma área de até 4 módulos fiscais, para sustentar o estabelecimento e a família. Além destes, silvicultores, aquicultores, pescadores, extrativistas, quilombolas, indígenas e os assentados da reforma agrária também são considerados agricultores familiares (MDA, 2016).

Quase $85 \%$ dos grupos ligados a produção animal e vegetal no Brasil são familiares (IBGE, 2006). A importância da agricultura familiar é evidenciada pelos dados que comprovam ser essencial para o abastecimento do mercado interno e controle da inflação do país onde os municípios brasileiros que possuem até 20 mil habitantes possuem $90 \%$ da sua base econômica voltada para esse tipo de atividade (FRANÇA, DEL GROSSI e MARQUES, 2009; NAVARRO, 2010). Além disso, possui grande relevância na absorção de empregos e na geração de alimentos, principalmente para subsistência das famílias produtoras.

Dada, sua menor incorporação tecnológica, tem-se que o setor se concentra mais nas funções de caráter social do que nas econômicas. No contexto de produção familiar a região Sul é a mais expressiva, tendo um PIB quase duas vezes maior que o da região Sudeste, pois é um setor dinâmico com grande capacidade de geração de riqueza. Isto está intrinsecamente ligado ao tipo de colonização da região, principalmente por alemães e italianos. Estados como Rio Grande do Sul e Paraná, se apresentam como alguns dos maiores produtores de grãos do país, mesmo depois da expansão da fronteira agropecuária.

Dados de 2004 demonstraram que do total do PIB do agronegócio familiar nacional, $44 \%$ é pertencente à região sul. Além do mais, a agricultura familiar tem participação significativa na riqueza nacional contribuindo com o Produto Interno Bruto (PIB) do agronegócio (Guilhoto et al., 2007). Os produtos oriundos da agricultura familiar correspondem a $10 \%$ do PIB e $38 \%$ do valor bruto da produção agropecuária nacional (MDA, 2014). 
A agricultura familiar quando inserida no mercado, reforça e valoriza o desenvolvimento local, além de promover o aumento da produção, e desenvolver a sociedade de maneira geral. Apesar dos agricultores familiares confrontarem obstáculos e adversidades para escoar sua produção, também constatam acesso aos mercados, estratégias fundamentais de comercialização de seus produtos. A integração entre produtores e consumidores fortalece a confiabilidade do produto, propicia a preservação da cultura regional, impulsiona o agricultor familiar e atrai consumidores pela diferenciação de produtos (SCHNEIDER; ESCHER, 2011).

\subsection{POLÍTICAS PÚBLICAS PARA A AGRICULTURA FAMILIAR}

As políticas públicas têm a finalidade de manter direitos assegurados na constituição para os cidadãos de uma forma ampla, ou até mesmo de um grupo social, étnico, cultural ou econômico por meio de programas, ações ou atividades desempenhadas pelo Estado seja direta ou indiretamente quando ligadas a entes públicos ou privados. Entretanto, diferentes definições são dadas às políticas públicas, embora a maioria dos autores as defina como ações governamentais para soluções de problemas (SOUZA, 2006).

Em apoio ao setor rural, a lei de política agrícola $n^{\circ} 8.171$ de 19 de janeiro de 1991, estabelece os princípios fundamentais para o apoio ao desenvolvimento rural em diversas áreas desde planejamento, mecanização, infraestrutura até linhas de crédito para os produtores (TEIXEIRA, 2002).

A primeira iniciativa de criação de política pública que auxiliou os pequenos produtores foi a criação do Programa Nacional de Fortalecimento da Agricultura Familiar (PRONAF), criado em 1995 com o intuito de financiar projetos de agricultores familiares, assentados da reforma agrária, cooperativas, além de povos e comunidades tradicionais. Dentro do PRONAF existem algumas outras ações governamentais que contribuem para a qualidade de vida e sustento dos agricultores familiares. A Assistência Técnica e Extensão Rural (ATER), por exemplo, busca auxiliar os produtores com a assistência técnica para aprimorar os processos de trabalho a fim de melhorar a qualidade de vida dos agricultores, além de assessorar na estruturação e melhoria da produção para os assentados (MDA, 2018).

O Programa de Aquisição de Alimentos (PAA), faz parte de uma das ações ligadas ao Fome Zero, onde desde 2003 auxilia pessoas que estão em situação de insegurança nutricional e alimentar e promove a inclusão social no campo, fortalecendo a agricultura familiar, pois a partir da atualização da Lei ${ }^{\circ}$ 12.512/2011 permitiu que o Governo Federal, Estadual e Municipal adquirisse alimentos diretamente dos pequenos produtores (BRASIL, 2011).

O PNAE instaurado pela Lei $n^{\circ} 11.947 / 2009$, garante que pelo menos $30 \%$ dos alimentos servidos nas escolas da rede pública de ensino sejam provenientes da agricultura familiar, por meio de chamadas públicas sem a necessidade de licitações (BRASIL, 2009).

Já o Programa Nacional de Crédito Fundiário (PNCF), possui 2 linhas de financiamento de imóveis rurais: uma delas é a de "Combate à Pobreza Rural" e a outra de "Consolidação da Agricultura Familiar". Ademais, prevê investimentos em estruturação básica do estabelecimento rural, projetos de recuperação ambiental e de convivência com a seca (MDA, 2018).

O Programa de Aceleração do Crescimento 2 (PAC2), deu prosseguimento às grandes obras de infraestrutura do Brasil. Neste programa, o Governo Federal 
por meio do Ministério do Desenvolvimento Agrário (MDA) entrega a municípios com até 50 mil habitantes equipamentos de grande porte como: retroescavadeiras, caminhões-caçamba, caminhões-pipa, entre outros. Consequentemente, os produtores são beneficiados pela melhoria do escoamento da sua produção e melhora na qualidade de vida (BRASIL, 2010).

Importante ação direcionada aos agricultores familiares o Programa de Cadastro de Terra e Regularização Fundiária, assegura a posse legal dos imóveis aos trabalhadores do campo estimulando sua permanência na zona rural. A mais, 0 Programa Terra Forte objetiva a implantação/modernização de cooperativas agroindustriais em assentamentos da Reforma Agrária, criados ou reconhecidos pelo INCRA, em todo o território nacional para estimular a renda nos assentamentos, valorizando o local onde estes produtores estão situados e mantendo-os fixados ao campo (MDA, 2018).

Garantia-Safra é um programa que assegura produtores, cuja renda familiar não exceda 1,5 salários mínimos por mês, a não perderem sua fonte de renda caso haja queda de pelo menos $50 \%$ na produção causados por problemas climáticos, como a seca ou excesso de chuvas. Para tanto, os agricultores devem possuir a Declaração de Aptidão ao Pronaf (DAP) e fazer a adesão ao programa (MDA, 2018).

A importância destas políticas está atrelada ao impulso que proporcionam a agricultura familiar, pois estas ações buscam atingir uma parte específica do mundo rural que, geralmente, encontra-se empobrecida e distante da modernização produtiva, mas que por outro lado, respeita o equilíbrio ambiental e as espécies. Sem dúvida esta preocupação com a agricultura familiar tem relação com a grande capacidade de produção de alimentos desta atividade no país. Estas políticas públicas são, seguramente, estímulos para que os agricultores permaneçam em suas propriedades produzindo alimentos de qualidade e prosperando no campo, além disso, garantem sua participação no comércio de alimentos, inclusive institucional.

\subsection{PROGRAMA NACIONAL DE ALIMENTAÇÃO ESCOLAR (PNAE) E SEGURANÇA ALIMENTAR E NUTRICIONAL}

$\mathrm{Na}$ década de 1930 iniciou-se as primeiras conjunturas da alimentação escolar no Brasil, sendo que os municípios e estados mais ricos dispuseram como responsabilidades o abastecimento da alimentação em suas respectivas redes de ensino (RIBEIRO; CERATTI; BROCH, 2013).

Nos anos 40, existia um movimento escolar com a finalidade de arrecadar recursos para fornecer alimentação aos estudantes, pois isto facilitava sua permanência no ambiente escolar assim como a redução da desnutrição dos infantes no país. Até este momento, o Governo Federal não participava destas iniciativas, somente em 31 de março de 1955 o presidente Juscelino Kubitschek criou a Campanha da Merenda Escolar (CME) por meio do Decreto n 37.106. Esta campanha foi se modificando e adaptando, e em 1979 intitulou-se Programa Nacional de Alimentação Escolar (PNAE), mais conhecido como "merenda escolar".

Desde seu surgimento nos anos 50 até os anos 60 este programa tinha auxílio de doações de gêneros alimentícios dos Estados Unidos como: farinha, trigo, soja e leite desnatado, entretanto quando as doações começaram a ficar escassas o Governo Federal Brasileiro iniciou a compra destes alimentos com recursos próprios (CHAVES e BRITO, 2006). O PNAE é gerenciado pelo Fundo Nacional de 
Desenvolvimento da Educação (FNDE) desde 1998, o qual é autarquia do Ministério da Educação (MEC), responsável pela normatização, monitoramento, gerenciamento e distribuição dos recursos providos pelo Governo Federal para as "Entidades Executoras".

Os valores repassados são considerados auxílios, pois não cobrem o custo total da alimentação dos estudantes. Os valores mais atualizados repassados pela União aos estados e municípios se dão por aluno para cada dia letivo de acordo com a modalidade de ensino. Para creches o valor é de $R \$ 1,07$, pré-escolas $R \$ 0,53$, escolas indígenas e quilombolas $R \$ 0,64$, ensino fundamental e médio $R \$ 0,36$, educação de jovens e adultos (EJA) $R \$ 0,32$, ensino integral $R \$ 1,07$, alunos do "Programa Mais Educação" $\mathrm{R} \$ 2,00$, alunos que frequentam o "Atendimento Educacional Especializado" no contraturno R\$0,53 (FNDE, 2018).

Estes valores são calculados com base no Censo Escolar do ano anterior e supervisionados pelo FNDE, Conselhos de Alimentação Escolar (CAE), Tribunal de Contas da União (TCU), Controladoria Geral da União (CGU) e Ministério Público. Graças a Lei $n^{\circ} 11.947$ de 16 de junho de 2009, o PNAE ampliou um benefício destinado aos estudantes das escolas públicas para os agricultores familiares, pois pelo menos $30 \%$ dos produtos utilizados na merenda escolar devem ser adquiridos da produção destes pequenos produtores, o que estimula 0 desenvolvimento econômico e sustentável das comunidades rurais locais (SEDUC, 2018).

Ao garantir a compra da agricultura familiar, o programa possibilita maior estabilidade à atividade agrícola destes agricultores, assegurando a circulação de dinheiro na economia da própria região onde os produtos foram produzidos. Entretanto, muitos municípios ainda estão em fase de implementação ${ }^{1}$ do programa embora já tenha se passado quase dez anos da mudança na legislação, ou seja, possuem índices baixos de aquisição de alimentos da agricultura familiar enquanto outros municípios caminham a passos largos ao adquirir 100\% dos alimentos da agricultura familiar. Uma política de tamanha importância para os escolares e produtores familiares de todo o país deve receber maior atenção quanto a sua efetiva execução.

Com isso, não basta termos uma política pública que busque incentivar o desenvolvimento da agricultura familiar se esta não estiver sendo executada em determinados locais. A busca pela execução plena do PNAE deve ser motivo de inquietação por parte de todos que participam do programa para que o mesmo possa realmente produzir os efeitos esperados a estudantes e agricultores familiares.

Os debates sobre fome foram introduzidos pelas obras de Josué de Castro, nas décadas de 1930 e 1940, onde certificou-se que o problema da insegurança alimentar no Brasil era resultante de um modelo de desenvolvimento social e econômico. A partir de então intensificou-se o entendimento sobre os motivos da miséria e da fome e ressaltou-se que elas eram a representação de uma sociedade injusta e desigual (PINHEIRO, 2009).

O desmedido trabalho de Josué de Castro, essencial para evidenciar o tema da fome no Brasil, se manteve postergado durante anos, sendo resgatado somente em meados da década de 1980 pelo Sociólogo Hebert José de Souza (Betinho). Evidencia-se que, foi espelhando-se nas lutas travadas por Betinho que se retomou no país a magnitude da erradicação da fome e em sua trajetória dedicou-se ao

\footnotetext{
${ }^{1}$ Fase de implementação se refere a dificuldade de manter constante e de forma ascendente a compra de alimentos para a merenda escolar da agricultura familiar local.
} 


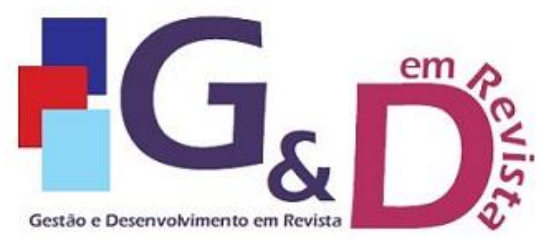

Gestão e Desenvolvimento em Revista V. 6, N. 2, jul-dez/2020, p. 03-19.

ISSN online: $2446-8738$

Artigo recebido em: 08/07/2020

Artigo aprovado em: 07/12/2020

projeto intitulado "Ação da Cidadania contra a fome, a Miséria e pela vida", manifestando a partir dele as diferentes formas que a fome pode manifestar (ALTEMBURG, 2014).

Na II Conferência Nacional de Segurança Alimentar e Nutricional conduzida em Olinda (2004), a elaboração brasileira para o conceito de segurança alimentar foi remodelada em lei:

\begin{abstract}
A segurança alimentar e nutricional consiste na realização do direito de todos ao acesso regular e permanente a alimentos de qualidade, em quantidade suficiente, sem comprometer o acesso a outras necessidades essenciais, tendo como base práticas alimentares promotoras da saúde que respeitem a diversidade cultural e que sejam ambiental, cultural, econômica e socialmente sustentáveis (Art. o da Lei no 11.346, CONSEA, 2006, p. 4).
\end{abstract}

É plausível atentar, enfim, a abrangência do conceito deste assunto, que contempla aspectos que tem efeito não apenas à disponibilidade de alimentos, mas também a sua qualidade nutritiva. Destaca os aspectos do acesso, qualidade e suficiência, valorizando os hábitos alimentares adequados, ao mesmo tempo em que posiciona a segurança alimentar e nutricional como condição elementar de cidadania (BECKER; ANJOS, 2010).

\title{
2. METODOLOGIA
}

Trata-se de uma pesquisa exploratória, cujo universo empírico é o município de São Gabriel, RS (Figura 1). Este tipo de pesquisa é desenvolvido no sentido de proporcionar uma visão geral acerca de determinado fato (GIL, 2008).

Com população de 60.105 habitantes, já teve grande destaque no setor pecuário, mas atualmente está cadeia tem perdido espaço para produção agrícola, principalmente para soja e arroz (IBGE, 2018). É neste cenário de produção de commodities, que alguns setores do município têm se organizado para fomentar a agricultura familiar local.

Figura 1. Estado do Rio Grande do Sul (RS), localizado na região Sul do Brasil à esquerda. À direita o Estado do RS com destaque no município de São Gabriel em vermelho.

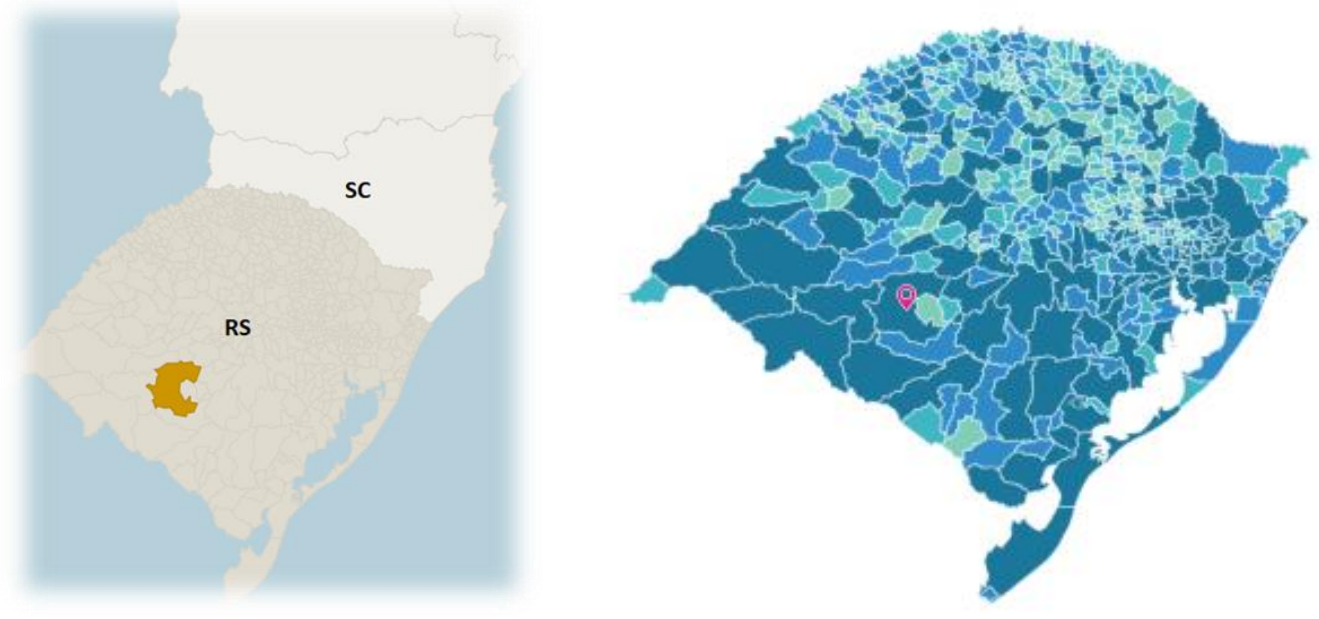

Fonte: IBGE, 2019 
Para a coleta de dados utilizou-se de entrevistas em profundidade e observação não participante, durante os meses de maio, junho e julho de 2018. Foram entrevistados cinco agricultores familiares individuais e representantes de duas cooperativas de produção agrícola. Estes agricultores são representativos na luta pela aquisição de alimentos através dos mercados institucionais e se mostraram disponíveis em participar da pesquisa.

Os agricultores cooperados que vendem seus gêneros alimentícios para a cooperativa em questão não têm ciência do destino destes alimentos, assim impedindo que a percepção dos mesmos seja avaliada. Também fez parte do estudo, entrevistada de forma complementar, a nutricionista do município, responsável pela gestão do PNAE. Para subsidiar a compreensão do universo empírico também se lançou mão de observação não participante e registro fotográfico (BAUER e GASKELL, 2012).

Os resultados foram analisados a luz da análise textual de discurso. Inicialmente procedemos com a desconstrução e unitarização do corpus, posteriormente realizamos a leitura e significação do material para posterior categorização dos discursos e finalmente prosseguimos com a descrição e interpretação (MORAES e GALIAZZI, 2016).

Assim, a partir da realização da entrevista com os participantes da Chamada Pública 001/2017 buscou-se saber informações a respeito de sua participação no PNAE e sua percepção a respeito deste programa. Ressalta-se também, que os entrevistados estão enumerados de 1 a 6 para não haver possibilidade de identificação, mantendo a privacidade dos entrevistados, a fim de evitar constrangimentos. Cabe ainda salientar que os agricultores residem em três municípios distintos: São Gabriel, Santa Margarida do Sul e Vila Nova do Sul.

\section{ANÁLISE E DISCUSSÃO DOS RESULTADOS}

Dentre os gêneros alimentícios fornecidos pelos agricultores estão: tempero verde, repolho, laranja, bergamota, mandioca, batata doce, leite, beterraba, couveflor, morango, carne bovina, charque e linguiça no período de agosto a dezembro de 2017.

Ao serem questionados sobre como tiveram ciência do processo de fornecimento de alimentos junto ao PNAE a maioria dos entrevistados obteve essa informação via Emater (Tabela 1).

Tabela 1 - Forma como os entrevistados acessam ao PNAE no município de São Gabriel

\begin{tabular}{lc}
\hline \multicolumn{1}{c}{ Fonte de informação } & $\mathbf{N}^{0}$ de entrevistados \\
\hline Cooperativa Central dos Assentamentos & 1 \\
do Rio Grande do Sul & 1 \\
EMATER - São Gabriel & 3 \\
EMATER - Vila Nova do Sul & 1 \\
Outros & \\
\hline
\end{tabular}

Fonte: Elaborada pelos Autores (2018).

Ao encontro deste questionamento ratifica a fala da nutricionista e gestora do programa no município que afirma que as chamadas públicas são comunicadas à Emater e divulgadas através de rádios e site da prefeitura, embora nenhum agricultor tenha citado estas últimas formas de comunicação mencionadas. 
Em relação as dificuldades enfrentadas durante o processo de seleção as percepções foram bastante divergentes, $50 \%$ dos entrevistados alegaram dificuldades com a documentação exigida para a participação no programa.

Questionados sobre como eram realizadas as entregas dos alimentos, os agricultores apontam que os pedidos eram feitos às quintas-feiras e as entregas às segundas-feiras, quando solicitadas pela nutricionista, por conta própria em veículo particular.

Alguns entrevistados afirmaram que, por vezes, aproveitavam para fazer as entregas em conjunto no mesmo veículo a fim de diminuir os custos, uma espécie de cooperativismo informal, uma vez que, de acordo com a fala da gestora do programa no município, a prefeitura não oferece apoio logístico aos produtores familiares.

Por outro lado, o fato de os alimentos serem entregues em um único local recebe destaque positivo entre os agricultores já que fazer as entregas diretamente nas cozinhas das escolas aumentaria consideravelmente os custos dado que estas escolas estão espalhadas pelo perímetro urbano e rural da cidade.

Quando tratado sobre sua percepção em relação ao PNAE as respostas foram bem diversificadas, mas em geral o que fez uma diferença significativa para os produtores foi a questão de geração de emprego e renda, pois desta forma eles tem a certeza de que vão conseguir vender o que produziram, além de que apenas um centro de distribuição facilitou a participação dos mesmos.

O Quadro 1 apresenta os pontos já apresentados, tanto positivos quanto negativos, citados pelos agricultores assim como a percepção da gestora do programa.

Quadro 1 - Pontos positivos e negativos do PNAE no município de São Gabriel segundo os agricultores e a gestora do programa

\begin{tabular}{|c|c|c|}
\hline Entrevistado & Pontos positivos & Pontos negativos \\
\hline 1 & Venda garantida; Centro de distribuição. & $\begin{array}{l}\text { Não cumprimento da demanda acordada; } \\
\text { Poder público municipal não apresenta } \\
\text { práticas. }\end{array}$ \\
\hline 2 & $\begin{array}{c}\text { Venda garantida; Pagamento garantido/em } \\
\text { dia. }\end{array}$ & $\begin{array}{l}\text { Valor de venda poderia ser mais alto, em } \\
\text { função da dificuldade de produção }\end{array}$ \\
\hline 3 & $\begin{array}{l}\text { Venda garantida; Centro de distribuição; } \\
\text { Preço adequado. }\end{array}$ & Documentação rigorosa. \\
\hline 4 & $\begin{array}{l}\text { Venda garantida; Pagamento e preço de } \\
\text { venda alto e em dia; Distribuição. }\end{array}$ & $\begin{array}{l}\text { Demanda que acompanhe o custo- } \\
\text { benefício da entrega. }\end{array}$ \\
\hline 5 & $\begin{array}{l}\text { Preço de venda alto e pagamento } \\
\text { garantido e em dia. }\end{array}$ & $\begin{array}{l}\text { Não cumprimento da demanda; Perda da } \\
\text { oportunidade de venda a terceiros. }\end{array}$ \\
\hline 6 & $\begin{array}{c}\text { Garantia de emprego e renda ao produtor } \\
\text { da região. }\end{array}$ & $\begin{array}{l}\text { Valor máximo de fornecimento muito } \\
\text { baixo }(\mathrm{R} \$ 20.000,00 \mathrm{ano}) \text {. }\end{array}$ \\
\hline Nutricionista & $\begin{array}{c}\text { Prioriza o comércio local; garante o } \\
\text { mínimo de } 30 \% \text { de produtos oriundos da } \\
\text { agricultura familiar e empreendedores } \\
\text { familiares. }\end{array}$ & $\begin{array}{c}\text { Falta de confiança entre produtores e } \\
\text { poder público; Falta de espírito } \\
\text { cooperativo; Logística; Falta de produção } \\
\text { organizada com diversificação de culturas. }\end{array}$ \\
\hline
\end{tabular}

Fonte: Elaborada pelos Autores (2018). 
Dentre essas dificuldades enfrentadas durante o processo de seleção, destaca-se a disponibilidade de tempo para organizar a documentação e o excesso de documentos requeridos. Em contrapartida, a outra metade dos agricultores familiares não apontou dificuldades e ressaltou ainda que o auxílio da Emater quanto as orientações sobre os documentos necessários e no preenchimento e organização da documentação, foi de grande valia no processo de seleção.

Além disso, Wagner (2017) aponta que a assistência técnica prestada pela Emater, em municípios de pequeno porte, foi muito importante na consolidação dos agricultores no programa, pois ajudou na organização dos mesmos e na elaboração dos projetos, além de tirar dúvidas, dentre elas, as relativas a documentação exigida. Nota-se que parte dos agricultores recorrem a Emater ao precisarem de auxílio, haja vista que o município de São Gabriel não realiza eventos que valorizem a agricultura familiar tampouco possui um cadastro de agricultores familiares no município, como atesta a gestora do programa.

Ainda com relação a dificuldades, no que tange ao restante do processo, a maioria dos participantes não acusou empecilhos, exceto dois entrevistados que não conseguiram entregar seus gêneros alimentícios ao final do contrato pois a demanda acordada não foi cumprida no prazo estipulado, o que acarretou na perda destes alimentos e a possível oportunidade de venda para outro interessado, não só se tratando de prejuízo financeiro, mas também desperdício de alimentos que estariam próprios para consumo corroborando com a resposta da nutricionista a qual apontou que todos alimentos entregues pelo produtores eram frescos e de boa qualidade.

Estes dados encontrados na pesquisa são similares aos encontrados por Bacarin et al (2017, p. 105):

[...] várias pesquisas têm verificado dificuldades para o agricultor acessar e permanecer neste mercado. Isso se relaciona a questões operacionais, estruturais e políticas como a organização dos agricultores, a dificuldade de logística, os preços pagos pelos produtos, a falta de formação e informação dos atores envolvidos, a falta de documentação dos agricultores, a desconfiança dos mesmos em relação ao poder público, a informalidade das agroindústrias, as estruturas inadequadas nas escolas, a falta de articulação entre os gestores e os agricultores e celeumas políticas.

Sabe-se que a formulação dos preços praticados no PNAE baseia-se por pesquisa em três mercados locais e se possível em feiras de agricultura familiar, caso isto não seja possível este levantamento de preços deve ser feito em mercados regionais, estaduais ou nacionais seguindo esta ordem. No valor final do produto deve estar incluso gastos com embalagem, transporte e outros encargos que o agricultor possa vir a ter.

Caso se trate de alimentos orgânicos e não seja possível a verificação dos preços, deve-se adotar os preços de produtos tradicionais acrescidos de $30 \%$ conforme resolução de FNDE $n^{\circ} 4$ de 2015 (BRASIL, 2015). No que se refere aos valores pagos aos produtores pelo PNAE, foi discutido se a participação valeria o custo-benefício. Neste caso, apenas um entrevistado alegou que por vezes não compensaria participar do programa visto que o alto custo dos combustíveis inviabiliza as entregas.

De outra forma, os demais entrevistados afirmam que a comercialização dos alimentos junto ao programa é mais vantajosa do que vender para outros tipos de comércio como mercados ou feiras, pois nestes espaços há uma concorrência direta 
dos produtos oriundos da agricultura convencional. Os dados apresentados por Alderete (2013) sobre mercados institucionais no município de Maçambará, também evidenciou que os preços pagos no PNAE foram maiores que os de mercado, desta forma, valorizando e incentivando a produção local.

Segundo os agricultores entrevistados, a distribuição dos gêneros alimentícios nas escolas de São Gabriel é feita por uma empresa terceirizada e esta empresa cumpre o papel de centro de distribuição onde os alimentos, inclusive os oriundos da agricultura familiar, são entregues e depois distribuídos para cada escola.

As falas dos agricultores são similares ao que é mostrado no estudo de Altemburg (2014), onde os agricultores, ao acessarem um mercado seguro, sentemse estimulados a produzirem mais e aumentarem suas rendas garantindo a manutenção familiar e da propriedade.

Já como pontos negativos, temos um problema sério em relação à quebra contratual por parte do Poder Público Municipal por não cumprir a demanda expedida no contrato, segundo os participantes. Essa situação se dá com o resguardo dado ao munícipio pelo edital e seguramente representa um dos fatores que mais gera insegurança e acarreta desinteresse por parte dos agricultores familiares.

Este problema acarreta em vários outros problemas, como a diminuição da credibilidade que os envolvidos tem com o programa fazendo com que possa haver a diminuição do número de participantes na chamada seguinte, além do prejuízo econômico dos pequenos agricultores, pois estes deixam de receber o que não puderam entregar além de que os alimentos deixam de estar na cadeia produtiva gerando um desperdício enorme enquanto já se sabe que boa parte de todos alimentos produzidos no mundo terminam no lixo.

De acordo com a FAO (2013) aproximadamente um terço dos alimentos para consumo humano é posto fora, à nível mundial, isso é equivalente a em média de 1,3 bilhões de toneladas desperdiçadas por ano. Por outro lado, o descumprimento da demanda acordada, a falta de políticas públicas próprias de assistência aos agricultores locais e divulgação limitada das chamadas públicas provocam dificuldades de acesso a este tipo de mercado além de criar instabilidade e desconfiança na relação entre os participantes do programa e o órgão público.

Quando se trata em sugestões para aumentar a participação dos produtores no PNAE, não restou dúvida de que existem muitos pontos a serem corrigidos. Este tipo de questionamento é um dos mais importantes dentro deste tipo de trabalho, pois é criada uma ponte de diálogo entre Poder Público e pequenos agricultores para o estreitamento de relações, afim de aumentar a valorização da agricultura familiar.

Finalmente, indagados sobre o interesse de uma nova participação em uma chamada pública futura, os entrevistados se mantiveram divididos dado o ambiente de incerteza, por exemplo, na questão contratual.

Para os insatisfeitos com o andamento do programa, se trata de um processo desgastante com retorno econômico baixo, pois houveram reajustes em diversos setores como o aumento do valor dos combustíveis, o que pode inviabilizar as entregas. Entretanto, os demais produtores ainda mantêm a convicção de que este programa é um complemento na renda e que participariam novamente desde que os valores se sobreponham ao custo de produção. 
Percebe-se também, com relação a possibilidade de uma nova participação no PNAE, que apenas 2 produtores não participem de uma nova chamada, isso significa uma perda de $33 \%$ do total de participantes o que emite um alerta para que medidas de adequação do programa local devam ser tomadas para que novos produtores participem, assim como mantenha ativos os que já participaram.

\section{CONCLUSÕES}

Com as imersões a campo foi possível constatar que existem fragilidades da estruturação e execução do PNAE no município de São Gabriel. As barreiras enfrentadas pelos agricultores familiares têm atuado de forma a não permitir a ampliação da compra de alimentos da agricultura familiar para a elaboração da merenda escolar no município fazendo com que este não consiga cumprir nem com a compra mínima em alguns meses.

Os resultados apresentados mostram de um lado a percepção do agricultor familiar e de outro o da gestão municipal do programa, percebe-se claramente que há uma divergência de olhares e compreensões acerca da implementação do programa no município. Porém, é evidente que existem pontos na gestão do programa que são bem avaliados pelos agricultores e que incentivam, mesmo que de forma tênue, a participação. A exemplo, as recorrentes falas dos gestores que apontam o compromisso e interesse da prefeitura em garantir pagamento sem atraso, valores atrativos e a possibilidade de entregas em apenas um centro de distribuição indicam alternativas para incentivar e facilitar a participação dos agricultores.

Por outro lado, o descumprimento da demanda acordada, a falta de políticas públicas municipais de assistência aos agricultores locais, como por exemplo, de auxílio em transporte para entrega dos alimentos, de orientação técnica, de substituição de produtos nos cardápios das escolas, dentre outras e divulgação limitada das chamadas públicas, provocam dificuldades de acesso a este tipo de mercado, além de criar instabilidade e desconfiança na relação entre os participantes do programa e o órgão público.

\section{REFERÊNCIAS}

ALDERETE, L. H. P. A contribuição do Programa Nacional de Alimentação Escolar (PNAE) no município de Maçambará/RS. 2013. 46 f. Trabalho de Conclusão de Curso (Tecnólogo em Desenvolvimento Rural) - Faculdade de Ciências Econômicas da UFRGS, Itaqui, 2013.

ALTEMBURG, S. G. N. A comida invisível: Representações sociais sobre a alimentação escolar entre a comunidade escolar e os agricultores familiares na região de Pelotas, RS. 2014. 209 f. Teses (Doutorado em Agronomia) - Faculdade de Agronomia Eliseu Maciel Universidade Federal de Pelotas, Pelotas, 2014.

BACARIN, J. G. et al. Indicadores de Avaliação das Compras da Agricultura Familiar para Alimentação Escolar no Paraná, Santa Catarina e São Paulo. Revista de Economia e Sociologia Rural, Piracicaba, v. 55, n. 1, p.103-122, jan./mar. 2017. 
BAUER, M.W.; GASKELL, G. Pesquisa Qualitativa com texto, imagem e som: um manual prático. (Trad. Pedrinho A. Guareschi). 10ª ed. Petrópolis. Rio Janeiro: Ed. Vozes. 516p. 2012.

BECKER, C., \& DOS ANJOS, F. S. (2010). Segurança alimentar e desenvolvimento rural: limites e possibilidades do Programa de Aquisição de Alimentos da agricultura familiar, em municípios do sul gaúcho. Segurança Alimentar e Nutricional, 17(1), 61-72.

BRASIL. Decreto no 1.946, de 28 de junho de 1996. Cria o programa nacional de fortalecimento da agricultura familiar - PRONAF, e dá outras providências. Diário Oficial da União, Brasília, DF, 1 julho 1996. Disponível em: Acesso em: 27 dez. 2017.

BRASIL. Lei Orgânica de Segurança Alimentar Nutricional (Losan). Lei $n^{\circ}$ 11.346, de 15 de setembro de 2006. Cria o Sistema Nacional de Segurança Alimentar e Nutricional-SISAN com vistas em assegurar o direito humano à alimentação adequada e dá outras providências. Diário Oficial da União 2006; 18 set. [Acessado 2010 jul 16]. Disponível em: https://www.planalto.gov.br/ccivil_03/_Ato2004-2006/2006/Lei/L11346.htm.

BRASIL. Lei no 11.947, de 16 de junho de 2009. Dispõe sobre o atendimento da alimentação escolar e do Programa Dinheiro Direto na Escola aos alunos da educação básica; altera as Leis nos 10.880, de 9 de junho de 2004, 11.273, de 6 de fevereiro de 2006, 11.507, de 20 de julho de 2007; revoga dispositivos da Medida Provisória no 2.178-36, de 24 de agosto de 2001, e a Lei no 8.913, de 12 de julho de 1994; e dá outras providências. Diário Oficial da República Federativa do Brasil, Brasília, DF, 17 jun. 2009. Disponível em: http://pesquisa.in.gov.br/imprensa/jsp/visualiza/index.jsp?jornal=1\&pagina=5\&data=1 7/06/2009 >. Acesso em: 30 jan. 2018.

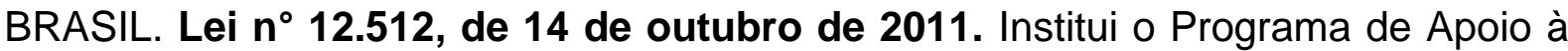
Conservação Ambiental e o Programa de Fomento às Atividades Produtivas Rurais; altera as Leis $\mathrm{n}^{\circ}$ 10.696, de 2 de julho de 2003, 10.836, de 9 de janeiro de 2004, e 11.326, de 24 de julho de 2006. Diário Oficial da República Federativa do Brasil, 14 Brasília, DF, 14 out. 2011. Disponível em:. Acesso em: 08 fev. 2018.

BRASIL. Ministério da Educação. Fundo Nacional de Desenvolvimento da Educação Resolução/CD/FNDE no 4, de 2 de abril de 2015. Altera a redação dos artigos 25 a 32 da Resolução/CD/FNDE no 26, de 17 de junho de 2013 no âmbito do Programa Nacional de Alimentação Escolar (PNAE). Diário Oficial da República Federativa do Brasil, Brasília, DF, 8 abr. 2015. Disponível em: <http:// portal.in.gov.br/>. Acesso em: 2 de ago. de 2018.

CHAVES, L. G.; BRITO, R. R. de. Políticas de Alimentação Escolar. Brasília: Centro de Educação a Distância - CEAD, Universidade de Brasília, 2006. 
FNDE, Fundo Nacional de Desenvolvimento da Educação. Aquisições agricultura familiar 2016. Disponível no endereço: http://www.fnde.gov.br/programas/pnae/pnaeconsultas/pnae-dados-da-agriculturafamiliar Arquivo capturado em 17 de set. 2018.

FOOD AND AGRICULTURE ORGANIZATION OF THE UNITED NATIONS -FAO. Food Wastage Photoprint: Impacts on natural resources. Summary Report. 2013.

FRANÇA, C. G. de; DEL GROSSI, M. E.; MARQUES, V. P. M. de A. O censo agropecuário 2006 e a agricultura familiar no Brasil. Brasília: MDA, 2009.

GIL, A. C. Métodos e técnicas de pesquisa social. $5^{a}$ ed., São Paulo: Atlas, 1999.

GIL, A. C. Métodos e técnicas de pesquisa social. $6^{\underline{a}}$ ed., São Paulo. Editora Atlas S.A [A1] [A2] ., 2008.

GUILHOTO, J. J. M. et al. PIB da Agricultura Familiar: Brasil - Estados. Ministério do Desenvolvimento Agrário (MDA). NEAD Estudos 19. Brasília, 2007. 172 p.

IBGE, Instituto Brasileiro de Geografia e Estatística. Censo Agropecuário 2006. Rio de Janeiro, 2006.

IBGE. Instituto Brasileiro de Geografia e Estatística. Censo Agropecuário 2010. Rio de Janeiro, Disponível em: https://www.ibge.gov.br/cidades-e-estados/rs/saogabriel.html. Arquivo capturado em 19 de dezembro de 2019.

MDA, Ministério do Desenvolvimento Agrário. O que é a agricultura familiar. 2016.

MDA, Ministério do Desenvolvimento Agrário. Políticas Públicas para a Agricultura Familiar. Disponível em: < http://www.mda.gov.br/sitemda/sites/sitemda/files/ceazinepdf/politicas_public as_baixa.pdf $>$. Arquivo capturado em 09 de jan. de 2018.

MDA, Ministério do Desenvolvimento Agrário. A agricultura familiar encerra 2013 com recordes e define novas metas no ano internacional do setor, 2014.

MORAES, R.; GALIAZZI, M. C. Análise textual discursiva. - 3a․ ed. - ljuí: Editora Unijuí, 2016. <http://portal.mda.gov.br/portal/saf/noticias/item?item_id=15658991>. Acesso em: 30 mai. 2019.

NAVARRO, Z. A agricultura familiar no Brasil: entre a política e as transformações da vida econômica. In: GASQUES, J. G.; NAVARRO, Z.; VIEIRA FILHO, J. G. E. (Org). A Agricultura Brasileira: desempenho, desafios e perspectivas. Brasília: Ipea, 2010. P. 185-209. 


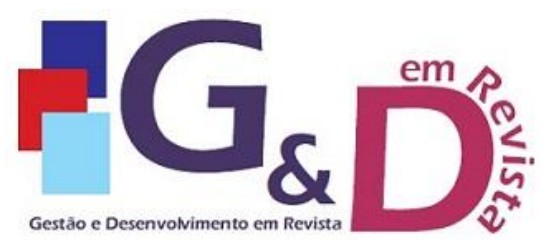

Gestão e Desenvolvimento em Revista V. 6, N. 2, jul-dez/2020, p. 03-19.

ISSN online: $2446-8738$

Artigo recebido em: 08/07/2020

Artigo aprovado em: 07/12/2020

Programa Nacional de Alimentação Escolar. Ciência e Saúde Coletiva, Rio de Janeiro, v. 18, n. 4, p. 927-935, abr. 2013. Disponível em: <https://doi.org/10.1590/S1413.1232013000400004>. Acesso em: 15 de fev. de 2018.

RIBEIRO, A. L., CERATTI, S., \& BROCH, D. T. (2013). Programa Nacional de Alimentação Escolar (PNAE) e a participação da agricultura familiar em municípios do Rio Grande do Sul. Revista GEDECON - Gestão e Desenvolvimento em Contexto, 1(1), 36-49.

SARAIVA, E. B., SILVA, A. P. F. D., SOUSA, A. A. D., CERQUEIRA, G. F., CHAGAS, C. M. D. S., \& TORAL, N. Panorama da compra de alimentos da agricultura familiar para o Programa Nacional de Alimentação Escolar. Ciência \& Saúde Coletiva, 18(4), 927-935, 2013.

SCHNEIDER, S.; ESCHER, F. A contribuição de Karl Polanyi para a sociologia do desenvolvimento rural. Sociologias, 2011, 13.27: 180-219.

SEDUC RS, Secretaria de educação do Estado do Rio Grande do Sul. Alimentação Escolar. Disponível em: Acesso em: 04 de jan. de 2018.

SOUZA, C. Políticas Públicas: uma revisão de literatura. Porto Alegre: Sociologia, 2006.

SPINELLI, M. A. S.; CANESQUI, A. M. O programa de alimentação escolar no estado de Mato Grosso: da centralização à descentralização (1979-1995). Revista de Nutrição, Campinas, v. 15, n. 1, p. 105-117, 2002.

TEIXEIRA, E. C. O papel das políticas públicas no desenvolvimento local e na transformação da realidade. Salvador: AATR, 2002.

TOMASETTO, M. Z. C.; LIMA, J. F.; SHIKIDA, P. F. A. Desenvolvimento local e agricultura familiar: o caso da produção de açúcar mascavo em Capanema - Paraná. Interações, Campo Grande, v. 10, n. 1, p. 21-30, 2009.

TOYOYOSHI, J. Y., OLIVEIRA, R. D., SANTOS, M. D., GALISA, M. S., \& GALANTE, A. P. Avaliação da aquisição de gêneros alimentícios provenientes da agricultura familiar para a alimentação escolar. Mundo Saúde, 37(3), 329-35, 2013.

TOMASETTO, M.Z.C.; LIMA, J.F.; SHIKIDA, P.F.A. Desenvolvimento local e agricultura familiar: o caso da produção de açúcar mascavo em CapanemaParaná. Interações, 2009, 10.1:21-30.

TRICHES, R. M.; SCHNEIDER, S. Alimentação escolar e agricultura familiar: reconectando o consumo à produção. Revista Saúde e Sociedade, São Paulo, v. 19, n. 4, p. 933-945, 2010. 


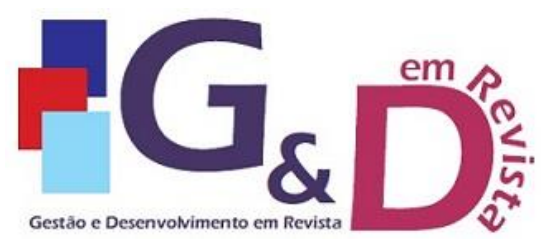

Gestão e Desenvolvimento em Revista V. 6, N. 2, jul-dez/2020, p. 03-19. ISSN online: $2446-8738$ Artigo recebido em: 08/07/2020 Artigo aprovado em: 07/12/2020

WAGNER, E. J. As contribuições do extensionismo rural da EMATER/RS ASCAR o PNAE em São Lourenço do Sul -RS. 2017. 49 f. Trabalho de Conclusão de Curso (Bacharelado em Desenvolvimento Rural) - Faculdade de Ciências Econômicas da UFRGS, Porto Alegre, 2017.

BEZERRA, I. V.; DA SILVA, E. L. Campanhas de Incentivo à Vendas como Fator de Motivação Organizacional. Revista Educação, Gestão e Sociedade, Ano 6, ํㅡ. 22, p. 1-17, 2016.

BUSSAB, W.O; MORETTIN, P.A. Estatística básica. São Paulo: Editora Saraiva, 2003.

Gestão de pessoas: o novo papel dos recursos humanos nas organizações. 14. ed. Rio de Janeiro: Campus, 1999.

CHIAVENATO, Idalberto. Administração Estratégica. São Paulo: Ed. Saraiva, 2003.

CHIQUIE, Marco Antônio. A força da equipe comercial no Distribuidor de TI. Abradisti, 2011. Disponível em: <https://itforum365.com.br/a-forca-da-equipecomercial-no-distribuidor-de-ti/>. Acesso em: 13 de maio de 2020.

FERREIRA, Rony Santos; FRANCO, Fabiana. O PAPEL DO LIDER NA MOTIVAÇÃO DE UMA EQUIPE DE VENDAS. Revista de Administração e Contabilidade - RAC, [S.I.], v. 2, n. 4, set. 2015.

FINK, Stephen L.; COHEN, Allan R. Comportamento organizacional. 10. ed. São Paulo: Atlas 2003.

FUTRELL, Charles. Vendas: fundamentos e novas práticas de gestão. 1. ed. São Paulo: Saraiva, 2003.

GENISELLI, André. CES 2017: Celebrando a História e o Futuro da Tecnologia. Revista PartnerSales, edição 96, Ano 10, p. 38-41, Janeiro-Fevereiro, 2017.

GAMBARDELLA, A., PANICO, C., VALENTINI, G. Strategic incentives to human capital. Strategic Management Journal, 36(1): 37-52, 2015.

GOLDSMITH, Marshall; LYONS, Laurence; FREAS, Alyssa. Coaching: o exercício da liderança. 10. ed. Rio de Janeiro: Elsevier, 2003.

GORDINHO, Mariano. ABRADISTI - Presença Regional das Revendas: Oportunidades de Distribuição nos Quatro Cantos do País. Revista Eletrolar, Ano 15, n‥ 97, 2014.

KIELWAGEN, Edson Klaus. Gestão de pessoas. Indaial SC: Ed. Uniasselvi, 2013.

KOTLER, Philip. Administração de marketing: a edição do novo milênio. 10. ed. São Paulo, 2000. 
LACOMBE, Francisco José Masset; HEILBORN, Gilberto Luiz José. Administração: Princípios e Tendências. São Paulo: Saraiva, 2003.

MAZER. Mazer Distribuidora. Disponível em: $<$ https://www.mazer.com.br/institucional/sobre-a-mazer>. Acesso em: 06 de maio de 2020.

MOSCOVICl, Fela. Equipes dão certo: a multiplicação do talento humano. 12. ed. Rio de Janeiro: José Olympio, 2003.

MILLER, D., XU, X., MEHROTRA, V. When is human capital a valuable resource? The performance effects of Ivy League selection among celebrated CEOs. Strategic Management Journal, 36(6): 930-944, 2015.

PONTES, Benedito Rodrigues. Avaliação de Desempenho: nova Abordagem. 9. ed. São Paulo: LTR, 2005.

RICHARDSON, Roberto Jarry. Pesquisa Social Métodos e Técnicas. 3. ed. São Paulo: Atlas, 1999.

SCHERMERHORN, John R. Administração: Conceitos Fundamentais. Rio de Janeiro: LTC, 2006.

SILVA, J. D.; VIEIRA, V. A.; FAIA, V.S.. Quando o Sistema de Controle Enfraquece o Desempenho com Vendas. Revista Brasileira de Marketing, Vol. 14. №. 1, p. 1-17, 2015.

SOUZA, Vital. Liderança, desenvolvimento de equipes de trabalho e personalidade. Adminstradores - O Portal de Administração. São Paulo, 2010. Disponível em: <http://www.administradores.com.br/informe-se/artigos/liderancadesenvolvimento-de-equipes-de-trabalho-e-personalidade/49934/>. Acesso em 06 de maio de 2020.

SPIRO, Rosann L.; RICH, Gregory A.; STANTON, William J. Gestão da força de vendas. 12. ed. São Paulo: McGraw-Hill, 2009.

STARR, E., GANCO, M., CAMPBELL, B.A. Strategic Human Capital Management in the Context of Cross-Industry and Within-Industry Mobility. Strategic Management Journal, 39 (8), 2226-2254, 2018.

VESCO, D. C. D.; BEUREN, I. M.; POPIK, F. Percepção de justiça na avaliação na avaliação de desempenho e satisfação do trabalho. Enfoque: Reflexão Contábil, vol. 35, no. 3, p. 121-138, 2016.

VOMBERG A., HOMBURG, C., BORNEMANN, T. Talented people and strong brands: the contribution of human capital and brand equity to firm value. Strategic Management Journal 36(13): 2122-2131, 2015. 